\title{
Research
}

Sunil M Shah, lain M Carey, Tess Harris, Stephen DeWilde and Derek G Cook

\section{Quality of prescribing in care homes and the community in England and Wales}

\begin{abstract}
Background

Care home residents are vulnerable to the adverse effects of prescribing but there is limited monitoring in the UK.
\end{abstract}

\section{Aim}

To compare prescribing quality in care homes in England and Wales with the community and with US nursing homes.

\section{Design and setting}

Cross-sectional analysis of a UK primary care database and comparison with the US National Nursing Home Survey including 326 general practices in 2008-2009 in England and Wales, with 10387 care home and 403259 community residents aged 65 to 104 years.

\section{Method}

Comparison of age- and sex-standardised use of 'concern' and common drug groups in the last 90 days and potentially inappropriate prescribing based on a consensus list of medications best avoided in older people (Beers criteria).

\section{Results}

Compared to the community, care home residents were more likely to receive 'concern' drugs, including benzodiazepines (relative risk $(R R)=2.05,95 \%$ confidence interval $(C)=1.90$ to 2.22), anticholinergic antihistamines ( $R R=2.78$, $95 \% \mathrm{Cl}=2.38$ to 3.23 ), loop diuretics ( $\mathrm{RR}=1.47$, $95 \% \mathrm{Cl}=1.41$ to 1.53$)$, and antipsychotics (RR = $22.7,95 \% \mathrm{Cl}=20.6$ to 24.9 ). Use of several common drug groups, including laxatives, antidepressants, and antibiotics, was higher, but use of cardiovascular medication was lower Thirty-three per cent ( $95 \% \mathrm{Cl}=31.7 \%$ to $34.3 \%$ ) of care home residents in England and Wales received potentially inappropriate medication, compared to $21.4 \%(95 \% \mathrm{Cl}=20.9 \%$ to $21.8 \%$ ) in the community. The potentially inappropriate prescribing rate in US nursing homes was similar to England and Wales.

\section{Conclusion}

Care home prescribing has the potential for improvement. High use of anticholinergic and psychotropic medication may contribute to functional and cognitive decline. The targeting and effectiveness of medication reviews in care homes needs to be improved.

\section{Keywords}

community; inappropriate prescribing; nursing homes; prescribing patterns; primary care.

\section{INTRODUCTION}

Prescribing quality is an important determinant of wellbeing for older people, and balancing demands for increased effective prescribing with the risk of adverse events is a challenge for primary care. Inappropriate or excessive use of a range of medication, including psychotropic and anticholinergic drugs, has been shown to increase mortality, hospital admission, falls, functional impairment, and cognitive decline. $^{2-4}$ Older people in care homes are particularly vulnerable to the adverse effects of medication, and high levels of potentially inappropriate prescribing have been reported among older people in care homes. ${ }^{4-6}$

Since 2004, the UK general medical services contract has incentivised medication review for all patients receiving repeat medication, but the content of reviews is not specified and prescribing in care homes is not nationally monitored. Prescribing quality is not within the remit of the UK care home inspection regime, although pharmacy management is included. ${ }^{7}$ This contrasts with the US, where nursing home prescribing has been subject to legislative control for a number of years, with legislation requiring that nursing home residents are not prescribed 'unnecessary' drugs. ${ }^{8}$ US regulation includes mandatory monthly medication reviews by consultant pharmacists, guided by national guidelines.

Limited information exists on the quality

SM Shah, MSc, FFPH, senior lecturer in public health; IM Carey, BSc, MSc, PhD, research fellow; T Harris, MSc, MD, MRCGP, senior lecturer in primary care and GP: $\mathbf{S}$ DeWilde, MD, MRCGP senior lecturer in primary care epidemiology and GP; DG Cook, BSc, MSc, PhD, professor of epidemiology, Division of Population Health Science and Education, St George's University of London.

\section{Address for correspondence}

Sunil M Shah, Division of Population Health Science of prescribing in UK care homes and few studies internationally allow a direct comparison between older people in different residential settings." This study compares prescribing quality in care home and community settings in England and Wales. Specifically, it compares prescribing of 'concern' drug groups with the potential for harmful excessive use, prescribing of commonly-used drugs, and the overall level of potentially inappropriate prescribing using the Beers criteria la consensus list of medication best avoided in older people). ${ }^{10}$ Additionally, it compares potentially inappropriate prescribing in nursing homes in England and Wales with the US.

\section{METHOD}

\section{Data sources}

The Health Improvement Network (THIN) is an established primary care database, which collects anonymised data from UK general practices and includes a full record of diagnosis and prescribing. ${ }^{11,12}$ THIN includes an identifier, family number, which allows practices to link patients who live in the same household or institution.

\section{Identifying care home residents}

Care homes in the UK are classified as either nursing or residential homes, and primary care physicians are responsible for prescribing in both. This research commissioned anonymised postcode linkage in THIN to identify patients who lived in postcodes that included a nursing or

and Education, St George's University of London, SW17 ORE.

E-mail: sushahasgul.ac.uk

Submitted: 6 September 2011; Editor's response: 26 October 2011; final acceptance: 6 December 2011.

CBritish Journal of General Practice

This is the full-length article (published online 30 Apr 2012) of an abridged version published in print. Cite this article as: Br J Gen Pract 2012; DOI: 10.3399/bjgp12X641447. 


\section{How this fits in}

Older care home residents are vulnerable to the adverse effects of medication but there is limited regulation or monitoring of care home prescribing in the UK. Care home residents are more likely to receive medication with the potential for harmful excess use, including psychotropic and anticholinergic medication, than their community counterparts. The rate of potentially inappropriate prescribing in nursing homes in the US and England and Wales is similar, despite stronger regulation in the US. There is potential for improving the quality of prescribing in care homes, and an approach targeted at risk, rather than repeat, prescribing may be more effective in improving wellbeing for older people.

residential home. Postcodes in the UK relate, on average, to 15 addresses.

Care home residents were identified based on the presence of either a specific record of residence in a care home or at least two other independent markers of care home residence. The independent markers were registered address in a care home postcode, a family number with four or more older people in a household; and a record of consultation in a care home. Most postcodes uniquely relate to a single care home, allowing care home type (nursing or residential) to be classified, but some care home residents were not classifiable $(n=$ 1403). ${ }^{13,14}$

It has previously been shown that the study approach identifies approximately $70 \%$ of older care home residents. ${ }^{13}$ Patients with no markers of care home residence were identified as living in the community and those with only one independent marker were excluded from analysis. This ensures that the community comparison group does not include care home patients..$^{13}$

\section{Participants}

The study included 10387 residents in care homes for older people and 403259 older people in the community aged 65-104 years, from 326 practices in England and Wales. All participants had at least 90 days' registration with their practice during the period March 2008 to February 2009.14

\section{Prescribing}

Any prescription in the last 90 days was identified, and medications were grouped according to the third level (paragraph) of the British National Formulary hierarchical classification of medications to identify any patient who had received that drug class in the last 90 days..$^{15}$ The occurrence of a medication review in the last year was identified by Read Codes for medication review in the primary care record.

\section{Drug groups}

'Concern' drug groups with the potential for harmful excessive use and resultant adverse outcomes were identified. These were selected primarily based on the Beers criteria but loop diuretics, corticosteroids, and antipsychotics were also included, based on their potential for inappropriate excessive use and risk of adverse events. Inclusion of drugs in the 'concern' group does not necessarily imply inappropriate prescribing and many of the drugs have indications in older people. This paper also presents common drug groups that featured in the top 10 drug groups prescribed in either care homes or the community.

\section{Potentially inappropriate prescribing}

The Beers criteria for potentially inappropriate prescribing lists drugs that are: (i) inappropriate at any dose for all older people and (ii) inappropriate above a certain dose threshold or for patients with specified comorbidities. ${ }^{10}$ The list does not include most antipsychotic medication.

The authors have previously modified the 2003 Beers criteria for use in a UK primary care database.16,17 In brief, drugs on the Beers criteria list, and their UK equivalents, were identified in the Multilex drug directory used by THIN, and receipt of a prescription for these drugs was identified. For this analysis, amitriptyline was excluded from the dose-independent criteria, on account of its appropriate use at low dose for neuropathic pain. This paper presents the proportion of patients receiving any Beerscriteria-inappropriate medication in the last 90 days and, for comparison with US data, patients receiving medication that is inappropriate at any dose, irrespective of comorbidity.

\section{US prescribing}

A separate analysis was conducted of data from the 2004 US National Nursing Home Survey; a survey undertaken in Medicare- or Medicaid-certified or state-registered nursing homes. ${ }^{18}$ This included 11860 nursing homes residents aged $\geq 65$ years with medication recorded, and identified patients receiving medication that is potentially inappropriate for all older people at any dose, according to the Beers criteria. 


\section{Predictors of potentially inappropriate prescribing}

Prescribing of Beers drugs that are inappropriate for all older people at any dose was examined by age, sex, region, area deprivation, dementia diagnosis, physical comorbidity, number of different drug classes received, and type of care home. Dementia was identified based on Read Codes for dementia used in the UK general medical services contract and additional codes for cognitive decline. ${ }^{19}$ For comorbidity, a simple count of the number of conditions recorded out of coronary heart disease, diabetes, heart failure, stroke, hypothyroidism, chronic obstructive pulmonary disease or asthma, Parkinson's disease, and active musculoskeletal conditions was used.

\section{Analysis}

For descriptive comparison, all results are directly standardised for age (5-year age bands) and sex to the combined care home population in the study sample. Predictors of prescribing were modelled using log binomial generalised estimating equations. These allow for clustering within practice lusing an exchangeable correlation structure), which produces robust standard errors. $^{20}$

For comparison of prescribing of specific drug groups between settings, models were developed for each drug group, and prevalence risk ratios (RRs) are presented for care homes compared to the community, adjusted for age and sex.

Predictors of inappropriate prescribing were examined by separate models for care home and community, initially adjusted for age and sex, and then additionally adjusted for region, area deprivation (community only), care home type, comorbidity, and number of drug classes.

\section{RESULTS}

Patient characteristics and overall prescribing

The mean number of different drug classes received by patients, in the last 90 days, was 4.9 in the community and 8.4 in care homes, with a small difference between nursing and residential homes; $81.4 \%$ of care home patients had received a medication review in the last year, compared to $67.8 \%$ in the community (Table 1).

\section{Prescribing in different settings in England and Wales}

'Concern' drug groups. Crude and ageadjusted comparison of prescribing in the community and care homes shows higher use of all 'concern' drug groups in care homes, with the exception of non-steroidal anti-inflammatory drugs (NSAIDs; Table 2). The most marked differences in medication use were for psychotropic medication, with high use of antipsychotic drugs ( $R R=22.7$, $95 \%$ confidence interval $[\mathrm{Cl}]=20.6$ to 24.9$)$ and benzodiazepines $(\mathrm{RR}=2.05,95 \% \mathrm{Cl}=$ 1.90 to 2.22). In addition, care home residents were significantly more likely to receive anticholinergic antihistamines $(\mathrm{RR}=2.78$, $95 \% \mathrm{Cl}=2.38$ to 3.23 ), loop diuretics ( $R R=$ 1.47, $95 \% \mathrm{Cl}=1.41$ to 1.53), and anticholinergic bladder medication $(\mathrm{RR}=$ $1.69,95 \% \mathrm{Cl}=1.52$ to 1.88 ). Differences between nursing and residential homes were

\section{Table 1. Characteristics of community and care home patients aged 65-104 years}

\begin{tabular}{|c|c|c|c|c|c|c|c|c|c|}
\hline \multirow[b]{2}{*}{ Characteristic } & \multicolumn{9}{|c|}{ England and Wales patients registered for at least 90 days with their general practice } \\
\hline & \multicolumn{2}{|c|}{ Community } & & \multicolumn{2}{|c|}{ All care homes } & \multicolumn{2}{|c|}{ Residential homes only } & \multicolumn{2}{|c|}{ Nursing homes only } \\
\hline \multirow[t]{2}{*}{ Mean age, years } & 74.7 & & & 85.5 & & 86.1 & & 84.9 & \\
\hline & $n$ & $\%$ & & $n$ & $\%$ & $n$ & $\%$ & $n$ & $\%$ \\
\hline Total patients & 403259 & 100 & & 10387 & 100 & 4715 & 100 & 4269 & 100 \\
\hline Number of males & 180658 & 44.8 & & 2405 & 23.2 & 975 & 20.7 & 1103 & 25.8 \\
\hline Mean number of medicines ${ }^{a}$ & 4.9 & - & & 8.4 & - & 8.1 & - & 8.8 & - \\
\hline \multirow[t]{2}{*}{ Record of medication review } & 273493 & 67.8 & & 8454 & 81.4 & 3828 & 81.2 & 3505 & 82.1 \\
\hline & & Crude & Standardised & & Standardised & & Standardised & & Standardised \\
\hline Disease prevalence & $n$ & $\%$ & $\%^{b}$ & $n$ & $\%^{\mathrm{b}}$ & $n$ & $\%^{\mathrm{b}}$ & $n$ & $\%^{b}$ \\
\hline Coronary heart disease & 68948 & 17.1 & 20.2 & 1995 & 19.2 & 910 & 19.3 & 793 & 18.6 \\
\hline Heart failure & 15946 & 4.0 & 8.0 & 947 & 9.1 & 462 & 9.6 & 352 & 8.3 \\
\hline Stroke or TIA & 17694 & 4.4 & 6.3 & 1864 & 18.0 & 695 & 15.0 & 915 & 21.3 \\
\hline COPD or asthma & 61333 & 15.2 & 13.6 & 1161 & 11.2 & 568 & 11.7 & 429 & 9.5 \\
\hline Diabetes & 52669 & 13.1 & 11.3 & 1421 & 13.7 & 624 & 13.7 & 589 & 13.5 \\
\hline Hypothyroidism & 36059 & 8.9 & 11.6 & 1317 & 12.6 & 633 & 13.1 & 513 & 12.3 \\
\hline Dementia & 6450 & 1.6 & 3.7 & 4256 & 41.0 & 1892 & 40.1 & 1870 & 43.6 \\
\hline Hypertension & 198734 & 49.3 & 56.8 & 4593 & 44.2 & 2123 & 44.7 & 1799 & 42.3 \\
\hline
\end{tabular}

${ }^{a}$ Number of different classes in the last 90 days. ${ }^{b}$ Directly age- and sex-standardised to the combined England and Wales care home population. COPD $=$ chronic obstructive pulmonary disease. $T I A=$ transient ischaemic attack. 
Table 2. Number (\%) of patients receiving 'concern' and common drug groups in the last 90 days in the community and care homes in England and Wales

\begin{tabular}{|c|c|c|c|c|c|c|}
\hline \multirow[b]{2}{*}{ Drug group } & \multicolumn{3}{|c|}{ Community ( $n=403$ 259) } & \multicolumn{2}{|c|}{ Care home ( $n=10387)$} & \multirow{2}{*}{$\begin{array}{c}\text { Care home versus community } \\
\qquad \mathbf{R R}^{\mathrm{b}}(95 \% \mathrm{Cl})\end{array}$} \\
\hline & $n$ & Crude \% & Standardised $\%{ }^{a}$ & $n$ & Standardised $\%^{\mathrm{a}}$ & \\
\hline \multicolumn{7}{|l|}{ Concern } \\
\hline Anticholinergic antihistamines & 3267 & 0.8 & 1.0 & 302 & 2.9 & 2.78 (2.38 to 3.23 ) \\
\hline Anticholinergic bladder & 8623 & 2.1 & 2.9 & 509 & 4.9 & 1.69 (1.52 to 1.88$)$ \\
\hline Antipsychotics & 3677 & 0.9 & 1.2 & 2173 & 21.0 & 22.7 (20.6 to 24.9 ) \\
\hline Benzodiazepines & 18849 & 4.7 & 7.4 & 1510 & 14.5 & 2.05 (1.90 to 2.22 ) \\
\hline Corticosteroids & 18187 & 4.5 & 4.8 & 526 & 5.1 & 1.04 (0.94 to 1.14 ) \\
\hline Loop diuretics & 37687 & 9.4 & 18.0 & 2755 & 26.5 & 1.47 (1.41 to 1.53$)$ \\
\hline NSAIDs & 34338 & 8.5 & 6.3 & 397 & 3.8 & $0.60(0.54$ to 0.66$)$ \\
\hline Opioids & 68829 & 17.1 & 20.1 & 2325 & 22.4 & 1.11 (1.05 to 1.17$)$ \\
\hline \multicolumn{7}{|l|}{ Common } \\
\hline Antibiotics & 68784 & 17.1 & 19.4 & 4089 & 39.3 & 1.98 (1.90 to 2.06$)$ \\
\hline Antidepressants & 41552 & 10.3 & 11.3 & 3897 & 37.5 & 3.30 (3.17 to 3.43 ) \\
\hline Aspirin & 115080 & 28.5 & 33.3 & 4607 & 44.4 & 1.33 (1.29 to 1.37$)$ \\
\hline Beta-blockers & 80359 & 19.9 & 21.3 & 1322 & 12.7 & 0.61 (0.57 to 0.64$)$ \\
\hline Calcium blockers & 94990 & 23.6 & 25.9 & 1401 & 13.5 & 0.54 (0.51 to 0.57) \\
\hline Enteral feeds & 3386 & 0.8 & 1.9 & 1037 & 10.0 & 6.40 (5.67 to 7.22$)$ \\
\hline Laxatives & 34350 & 8.5 & 14.5 & 4993 & 48.1 & 3.32 (3.16 to 3.48 ) \\
\hline Lipid lowering & 155376 & 38.5 & 30.9 & 2675 & 25.8 & 0.87 l0.83 to 0.90 \\
\hline Paracetamol & 52822 & 13.1 & 20.4 & 3912 & 37.6 & 1.79 (1.70 to 1.89$)$ \\
\hline Proton pump inhibitors & 84090 & 20.9 & 23.4 & 3603 & 34.7 & $1.46(1.41$ to 1.51$)$ \\
\hline Renin-angiotensin system & 144562 & 35.9 & 36.9 & 2323 & 22.4 & 0.62 (0.59 to 0.65 ) \\
\hline Thiazides and related & 70364 & 17.5 & 18.8 & 833 & 8.0 & 0.42 (0.39 to 0.45 ) \\
\hline
\end{tabular}

generally small but use of anticholinergic antihistamine and antispasmodic drugs was higher in nursing homes.

Common drug groups. Care home residents were more likely to receive eight of the 13 common drug groups (Table 2), including antibiotics ( $\mathrm{RR}=1.98,95 \% \mathrm{Cl}=1.90$ to 2.06$)$, antidepressants $(\mathrm{RR}=3.30,95 \% \mathrm{Cl}=3.17$ to 3.43), laxatives ( $R R=3.32,95 \% \mathrm{Cl}=3.16$ to 3.48), and enteral feeding supplements (RR $=6.40,95 \% \mathrm{Cl}=5.67$ to 7.22 ) . Cardiovascular medications were less likely to be used in care homes. Stratification of care home patients by dementia diagnosis did not markedly change the findings.
Prevalence of potentially inappropriate prescribing

Of care home patients, 33.0\% $195 \% \mathrm{Cl}=31.7$ to 34.3 received at least one Beers-criteriainappropriate medication in the last 90 days compared to $21.4 \%(95 \% \mathrm{Cl}=20.9$ to 21.8$)$ in the community. There was little difference between nursing and residential homes (Table 3).

\section{Comparison with the US}

In the 2004 US National Nursing Home Survey, ${ }^{18} 23.9 \% \quad(95 \% \quad \mathrm{Cl}=23.0$ to 24.9$)$ received a drug that was potentially inappropriate, according to Beers criteria, for all older people at any dose. This compares

Table 3. Number (\%) of patients receiving Beers-criteria potentially inappropriate medication by residential setting in the last 90 days in the community and care homes in England and Wales

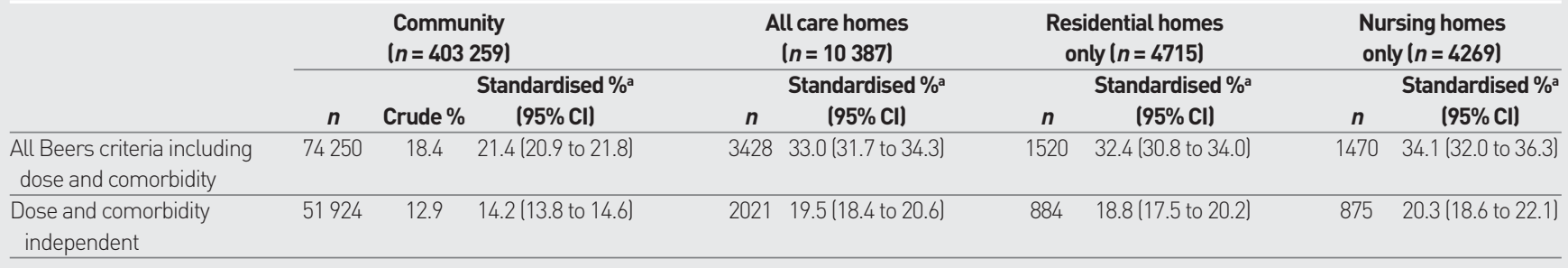

${ }^{a}$ Directly age- and sex-standardised to the combined England and Wales care home population. 
Table 4. Number $(\%)$ of patients receiving the most common Beerscriteria potentially inappropriate medications for all older people irrespective of dose in England and Wales (2008) and US nursing homes (2004)

\begin{tabular}{|c|c|c|c|c|}
\hline \multirow[b]{2}{*}{ Drug } & \multicolumn{2}{|c|}{$\begin{array}{l}\text { England and Wales } \\
\qquad(n=4269)\end{array}$} & \multicolumn{2}{|c|}{$\begin{array}{c}\text { US } \\
(n=11860)\end{array}$} \\
\hline & $n$ & $\%$ & $n$ & $\%$ \\
\hline Amiodarone & 39 & 0.9 & 213 & 1.8 \\
\hline Anticholinergic antispasmodics & 29 & 0.7 & 141 & 1.2 \\
\hline Anticholinergic antihistamines & 154 & 3.6 & 424 & 3.6 \\
\hline Bisacodyla & 66 & 1.5 & 376 & 3.2 \\
\hline Clonidine & 2 & 0.0 & 414 & 3.5 \\
\hline Diazepam & 179 & 4.2 & 78 & 0.7 \\
\hline Dipyridamole (short acting) & 27 & 0.6 & 33 & 0.3 \\
\hline Doxazocin & 60 & 1.4 & 125 & 1.1 \\
\hline Doxepin & 4 & 0.1 & 48 & 0.4 \\
\hline Estrogens (oral without progesterone) & 0 & 0 & 142 & 1.2 \\
\hline Fluoxetine & 146 & 3.4 & 371 & 3.1 \\
\hline Naproxen & 12 & 0.3 & 132 & 1.1 \\
\hline Nifedipine (short acting) & 4 & 0.1 & 197 & 1.7 \\
\hline Nitrazepam & 43 & 1.0 & 0 & 0.0 \\
\hline Nitrofurantoin & 143 & 3.3 & 193 & 1.6 \\
\hline Oxybutynin (short acting) & 66 & 1.5 & 370 & 3.1 \\
\hline
\end{tabular}

${ }^{a}$ Except for patients receiving opiates. Only medications received by at least $0.4 \%$ of nursing home residents in either country shown. with $20.3 \%(95 \% \mathrm{Cl}=18.6$ to 22.1$)$ in England and Wales nursing homes and $14.2 \%(95 \% \mathrm{Cl}$ $=13.8$ to $14.6 \mathrm{f}$ in the community. A comparison of the most common potentially inappropriate medication from the Beers criteria in nursing homes in the US and England and Wales is presented in Table 4.

Predictors of inappropriate prescribing

Table 5 shows age- and sex-adjusted predictors of Beers criteria inappropriate prescribing, in the community and in care homes in England and Wales. In both settings, the number of drugs received was strongly associated with inappropriate prescribing. In the community, dementia diagnosis had little effect on the likelihood of receiving potentially inappropriate medication, while in care homes, potentially inappropriate prescribing was less common in patients with dementia. It should be noted that the Beers criteria do not include most antipsychotic medications, which are more commonly prescribed in patients with dementia. Other comorbidity was associated with inappropriate prescribing in both settings but the effect was weaker in care homes.

After full adjustment, the number of drugs remained a strong and persistent predictor of inappropriate prescribing in both care homes and the community. However, the number of comorbid conditions did not predict inappropriate prescribing in either setting after full adjustment.

\section{DISCUSSION}

\section{Summary}

In England and Wales, older care home residents, compared to community residents, experience a higher burden of prescribing of medication with the potential for harmful excessive use and adverse events, including psychotropic medication and anticholinergic drugs. One-third of care home residents in England and Wales

Table 5. Predictors of Beers-criteria potentially inappropriate prescribing in the community and care homes

\begin{tabular}{|c|c|c|c|c|c|c|c|c|}
\hline \multirow[b]{2}{*}{ Factor } & \multicolumn{4}{|c|}{ Community ( $n=403259$ ) } & \multicolumn{4}{|c|}{ Care homes $(n=10387)$} \\
\hline & RR1 & $95 \% \mathrm{Cl}$ & RR2 & $95 \% \mathrm{Cl}$ & RR1 & $95 \% \mathrm{Cl}$ & RR2 & $95 \% \mathrm{Cl}$ \\
\hline \multicolumn{9}{|c|}{ Care home type } \\
\hline Residential & & & - & - & 1 & - & 1 & - \\
\hline Nursing & & & - & - & 1.09 & 1.02 to 1.18 & 1.04 & 0.96 to 1.11 \\
\hline Unclassified & & & - & - & 1.00 & 0.90 to 1.11 & 1.04 & 0.94 to 1.14 \\
\hline \multicolumn{9}{|l|}{ Dementia } \\
\hline No & 1 & - & - & - & 1 & - & 1 & - \\
\hline Yes & 1.06 & 1.01 to 1.12 & 0.99 & 0.94 to 1.04 & 0.77 & 0.72 to 0.82 & 0.87 & 0.81 to 0.92 \\
\hline \multicolumn{9}{|c|}{ Other comorbidities } \\
\hline 0 & 1 & - & - & - & 1 & - & 1 & - \\
\hline 1 & 1.56 & 1.53 to 1.60 & 0.87 & 0.86 to 0.89 & 1.11 & 1.04 to 1.20 & 0.92 & 0.86 to 0.98 \\
\hline 2 & 1.99 & 1.94 to 2.04 & 0.79 & 0.77 to 0.80 & 1.23 & 1.14 to 1.34 & 0.87 & 0.80 to 0.94 \\
\hline 3 & 2.42 & 2.35 to 2.49 & 0.76 & 0.74 to 0.78 & 1.31 & 1.18 to 1.46 & 0.84 & 0.75 to 0.93 \\
\hline$\geq 4$ & 2.88 & 2.78 to 2.99 & 0.77 & 0.74 to 0.80 & 1.30 & 1.12 to 1.50 & 0.77 & 0.67 to 0.88 \\
\hline \multicolumn{9}{|c|}{ Number of drug classes } \\
\hline $0-2$ & 1 & - & - & - & 1 & - & 1 & - \\
\hline 3-5 & 4.63 & 4.45 to 4.82 & 4.89 & 4.69 to 5.09 & 3.16 & 2.22 to 4.50 & 3.22 & 2.26 to 4.59 \\
\hline $6-10$ & 9.43 & 9.06 to 9.82 & 10.6 & 10.1 to 11.0 & 5.89 & 4.18 to 8.31 & 6.10 & 4.32 to 8.60 \\
\hline$\geq 11$ & 16.2 & 15.5 to 16.9 & 19.1 & 18.3 to 20.0 & 9.42 & 6.67 to 13.3 & 9.91 & 6.99 to 14.0 \\
\hline
\end{tabular}

$R R 1=$ Adjusted for age and sex. $R R 2$ = Adjusted for age, sex region, area deprivation (community only), care home type (care home only), dementia, comorbidity score, and number of drug classes. 
receive a potentially inappropriate medication according to the full Beers criteria. Potentially inappropriate medication use in nursing homes in England and Wales is similar to that in the US.

\section{Strengths and limitations}

Comparisons of prescribing quality between settings based on published studies are difficult, due to different approaches to implementation of Beers or similar criteria. ${ }^{21}$ The present study overcomes this problem by making comparisons using the same approach to criteria implementation in each setting.

The Beers criteria were developed in the US, and some have questioned the appropriateness of their application in Europe, on account of differences in practice and drug availability. ${ }^{22}$ The present results do not support this concern, as similar medications make a large contribution to inappropriate prescribing in both countries. Other newer measures of prescribing quality are available but the Beers criteria have the advantage of simplicity, especially where recording of comorbidity may vary between settings. The analysis of 'concern' drug groups in this study allows an alternate description of prescribing quality, by capturing prescribing across a range of medications that put older people at risk of serious adverse events through excessive use.

The analysis did not adjust comparisons between settings for comorbidities or polypharmacy. The rationale for this is that many drugs, such as anticholinergic and psychotropic medication, impair functional status and their impact on quality of life will be greater in patients with high levels of frailty or comorbidity. Adjustment for comorbidity may mask poor prescribing to vulnerable older people and give a falsely optimistic estimate of potentially harmful prescribing in care homes. Furthermore, differences in recording of comorbidities between settings would lead to biased estimates after adjustment.

\section{Comparison with existing literature}

The findings of this study are consistent with existing studies that describe high use of psychotropic and potentially inappropriate medication in US nursing home settings. 5,9,23 In terms of prevalence and characteristics of inappropriate prescribing, the present findings are very similar to a recent Australian study. ${ }^{6}$ Studies that allow comparison between residential settings are limited. A recent regional Scottish study described a $30 \%$ higher unadjusted use of potentially inappropriate medication in care homes compared to the community, and a US study that examined inappropriate prescribing in three residential settings showed higher levels of inappropriate prescribing in nursing homes compared to the general community. ${ }^{9,24}$ The present authors, and others, have previously described the strong relationship between polypharmacy and receipt of potentially inappropriate medication and the present findings are consistent with this explanation for higher levels of inappropriate prescribing in care homes. ${ }^{17,22,24}$

\section{Implications for practice and research}

The high use of antipsychotic medication in care homes is a well-recognised concern and the focus of a national policy initiative. ${ }^{25}$ The authors have previously described antipsychotic prescribing in care homes and most prescribing is to patients with dementia without a diagnosis of severe mental illness. ${ }^{26}$ The higher use of benzodiazepines and anticholinergic medication in care homes is a concern, as these drugs have been specifically identified as leading to functional impairment., ${ }^{2,3}$ The lower use of NSAIDs in care homes suggests that concerns over adverse events in older people has influenced prescribing but this finding needs to be considered in the context of the overall quality of pain management, which is beyond the scope of this study.

High use of loop diuretics, despite similar heart failure prevalence to the community, suggests either inadequate recording of heart failure or inappropriate use of diuretics for the management of dependent oedema. The authors have previously found that chronic disease may be under-identified in UK care homes and that prescribing of angiotensin-converting enzyme inhibitors for heart failure was lower in care homes than in the community.13,14 Overall, the markedly lower use of cardiovascular medication in care homes compared to the community is noteworthy. The most common indication for prescribing cardiovascular medications is treatment of hypertension, which is less likely to be diagnosed in care home patients. ${ }^{13}$ Further work is required to determine whether this lower use of cardiovascular medication in care homes is appropriate.

The high use of laxative medicines and nutritional supplements, although not necessarily a risk for older people, suggests a need for improved dietary management and reinforces concerns over nutrition in care homes. ${ }^{27,28}$ Higher antibiotic use in care 
homes may be appropriate, given resident frailty, but highlights the risk of antibiotic resistance in communal settings and the need for vigilance.

The strong association between polypharmacy and potentially inappropriate prescribing, prima facie, supports UK policy, which incentivises medication reviews for patients on repeat medication. However, as the vast majority of patients in care homes receive multiple medications, such an approach will lack specificity in care homes. Furthermore, evidence suggests that total drug use is less important than the contribution of specific drugs to functional impairment in older people, and the authors have previously shown that increased prescribing, as a result of the Quality and Outcomes Framework, has not necessarily increased potentially inappropriate prescribing. ${ }^{2,16}$ This suggests an approach targeted at risk, rather than repeat, prescribing may be more effective in improving wellbeing for older people.

The comparison with the US, although subject to caveats inherent in such international comparisons, suggests that the quality of prescribing in UK nursing homes is similar, at least based on the measures in the Beers criteria. This is surprising, as US nursing homes are subject to legislative regulation that includes monitoring of many drugs included in the Beers criteria. ${ }^{8}$ The comparison, in this study, between community and care home settings in the UK suggests that higher uptake of incentivised reviews in care homes does not prevent higher levels of inappropriate prescribing. This emphasises the need for additional effective interventions to improve prescribing quality, in addition to either regulation or incentivised medication reviews. This conclusion is consistent with evidence that questions the effectiveness of medication reviews in care homes and mandatory drug reviews in the US. ${ }^{29-31}$

In conclusion, there is potential for improving the quality of prescribing in care homes. In particular, reducing the high use of anticholinergic and psychotropic medication could improve function and wellbeing in a vulnerable population. Improving prescribing in care homes presents a challenge to physicians, who need to balance the increasing demands for effective prescribing with the need to minimise adverse events. There is a need for evidence-based prescribing interventions in care homes, which are more effective and focused than current incentivised medication reviews. ${ }^{29,32}$ 


\section{REFERENCES}

1. Rochon P, Gurwitz JH. Prescribing for seniors. Neither too much nor too little. JAMA 1999; 282(2): 113-115.

2. Hilmer SN, Mager DE, Simonsick EM, et al. A drug burden index to define the functional burden of medications in older people. Arch Intern Med 2007; 167(8): 781-787.

3. Glass J, Lanctôt KL, Herrmann N, et al. Sedative hypnotics in older people with insomnia: meta-analysis of risks and benefits. BMJ 2005; 331(7526): 1169.

4. Lau DT, Kasper JD, Potter DE, et al. Hospitalization and death associated with potentially inappropriate medication prescriptions among elderly nursing home residents. Arch Intern Med 2005; 165(1): 68-74.

5. Beers MH, Ouslander JG, Fingold SF, et al. Inappropriate medication prescribing in skilled-nursing facilities. Ann Intern Med 1992; 117(8): 684-689

6. Stafford AC, Alswayan MS, Tenni PC. Inappropriate prescribing in older residents of Australian care homes. J Clin Pharm Ther 2011; 36(1): 33-44.

7. Commission for Social Care Inspection. The state of social care in England 2007-08. London: Commission for Social Care Inspection, 2009.

8. Hughes CM, Roughead E, Kerse N. Improving use of medicines for older people in long-term care: contrasting the policy approach of four nations. Healthc Policy 2008; 3(3): 1-14.

9. Rigler SK, Perera S, Jachna C, et al. Comparison of the association between disease burden and inappropriate medication use across three cohorts of older adults. Am J Geriatr Pharmacother 2004; 2(4): 239-247.

10. Fick DM, Cooper JW, Wade WE, et al. Updating the Beers criteria for potentially inappropriate medication use in older adults: results of a US consensus panel of experts. Arch Intern Med 2003; 163(22): 2716-2724.

11. Bourke A, Dattani H, Robinson M. Feasibility study and methodology to create a quality-evaluated database of primary care data. Inform Prim Care 2004: 12(3): 171-177.

12. Lewis JD, Schinnar R, Bilker WB, et al. Validation studies of the health improvement network (THIN) data base for pharmacoepidemiology research. Pharmacoepidemiol Drug Saf 2007; 16(4): 393-401.

13. Shah SM, Carey IM, Harris T, et al. Identifying the clinical characteristics of older people living in care homes using a novel approach in a primary care database. Age Ageing 2010; 39(5): 617-623.

14. Shah SM, Carey IM, Harris T, et al. Quality of chronic disease care for older people in care homes and the community in a primary care pay for performance system: retrospective study. BMJ 2011; 342: d912

15. British Medical Association and the Royal Pharmaceutical Society. British National Formulary. London: BMJ Publishing group and RPS Publishing, Royal Pharmaceutical Society of Great Britain, 2010.

16. De Wilde S, Carey IM, Harris T, et al. Trends in potentially inappropriate prescribing in older UK primary care patients. Pharmacoepidemiol Drug Saf 2007; 16(6): 658-667.
17. Carey IM, De Wilde S, Harris T, et al. What factors predict potentially inappropriate primary care prescribing in older people? Drugs Aging 2008; 25(8): 693-706.

18. Jones AL, Dwyer LL, Bercovitz AR, Strahan, GW. The National Nursing Home Survey: 2004 overview. Vital Health Stat 132009 ; (167): 1-155.

19. Department of Health. New GMS contract QOF implementation. Dataset and business rules. London: Department of Health, 2006.

20. Barros AJ, Hirakata VN. Alternatives for logistic regression in cross-sectional studies: an empirical comparison of models that directly estimate the prevalence ratio. BMC Med Res Methodol 2003; 3: 21.

21. Gallagher $\mathrm{P}, \mathrm{Barry} \mathrm{P}, \mathrm{O}$ 'Mahony D. Inappropriate prescribing in the elderly. $J$ Clin Pharm Ther 2007; 32(2): 113-121.

22. Fialová D, Topinková E, Gambassi G, et al. Potentially inappropriate medication use among elderly home care patients in Europe. JAMA 2005; 293(11): $1348-1358$

23. Stevenson DG, Decker SL, Dwyer LL, et al. Antipsychotic and benzodiazepine use among nursing home residents: findings from the 2004 National Nursing Home Survey. Am J Geriatr Psychiatry 2010; 18(12): 1078-1092.

24. Barnett K, McCowan C, Evans JM, et al. Prevalence and outcomes of use of potentially inappropriate medicines in older people: cohort study stratified by residence in nursing home or in the community. BMJ Qual Saf 2011; 20(3): 275-281.

25. Banerjee S. The use of antipsychotic medication for people with dementia: time for action. A report for the Minister of State for Care Services. London: Department of Health, 2009.

26. Shah SM, Carey IM, Harris T, et al. Antipsychotic prescribing to older people living in care homes and the community in England and Wales. Int J Geriatr Psychiatry 2011; 26(4): 423-434

27. Hosia-Randell H, Suominen M, Muurinen S, Pitkälä KH. Use of laxatives among older nursing home residents in Helsinki, Finland. Drugs Aging 2007; 24(2): 147-154.

28. McMurdo ME, Witham MD. Health and welfare of older people in care homes. BMJ 2007; 334(7600): 913-914.

29. Loganathan M, Singh S, Franklin BD, Bottle A, Majeed A. Interventions to optimise prescribing in care homes: systematic review. Age Ageing 2011; 40(2): 150-162.

30. Lapane KL, Hughes CM, Quilliam BJ. Does incorporating medications in the surveyors' interpretive guidelines reduce the use of potentially inappropriate medications in nursing homes? J Am Geriatr Soc 2007; 55(5): 666-673.

31. Briesacher $B$, Limcangco $R$, Simoni-Wastila $L$, et al. Evaluation of nationally mandated drug use reviews to improve patient safety in nursing homes: a natural experiment. J Am Geriatr Soc 2005; 53(6): 991-996.

32. Forsetlund L, Eike MC, Gjerberg E, Vist GE. Effect of interventions to reduce potentially inappropriate use of drugs in nursing homes: a systematic review of randomised controlled trials. BMC Geriatr 2011; 11: 16. 